This article was downloaded by: [UNSW Library]

On: 14 October 2013, At: 16:56

Publisher: Routledge

Informa Ltd Registered in England and Wales Registered Number: 1072954 Registered office: Mortimer House, 37-41 Mortimer Street, London W1T 3J H, UK

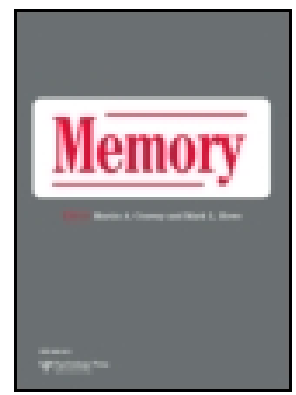

\title{
Memory
}

Publication details, including instructions for authors and subscription information: http:// www. tandfonline.com/loi/pmem20

\section{Autobiographical memory bias in social anxiety}

Julie Krans ${ }^{a}$, J une de Bree ${ }^{b} \&$ Richard A. Bryant ${ }^{a}$

${ }^{a}$ School of Psychology, The University of New South Wales, Sydney, Australia

${ }^{b}$ Department of Clinical Psychology, Radboud University Nijmegen, The Netherlands Published online: 10 Oct 2013.

To cite this article: J ulie Krans, J une de Bree \& Richard A. Bryant, Memory (2013): Autobiographical memory bias in social anxiety, Memory

To link to this article: http:// dx.doi.org/ 10.1080/09658211.2013.844261

\section{PLEASE SCROLL DOWN FOR ARTICLE}

Taylor \& Francis makes every effort to ensure the accuracy of all the information (the "Content") contained in the publications on our platform. However, Taylor \& Francis, our agents, and our licensors make no representations or warranties whatsoever as to the accuracy, completeness, or suitability for any purpose of the Content. Any opinions and views expressed in this publication are the opinions and views of the authors, and are not the views of or endorsed by Taylor \& Francis. The accuracy of the Content should not be relied upon and should be independently verified with primary sources of information. Taylor and Francis shall not be liable for any losses, actions, claims, proceedings, demands, costs, expenses, damages, and other liabilities whatsoever or howsoever caused arising directly or indirectly in connection with, in relation to or arising out of the use of the Content.

This article may be used for research, teaching, and private study purposes. Any substantial or systematic reproduction, redistribution, reselling, loan, sub-licensing, systematic supply, or distribution in any form to anyone is expressly forbidden. Terms \& Conditions of access and use can be found at http://www.tandfonline.com/page/terms-and-conditions 


\title{
Autobiographical memory bias in social anxiety
}

\author{
Julie Krans ${ }^{1}$, June de Bree ${ }^{2}$, and Richard A. Bryant ${ }^{1}$ \\ ${ }^{1}$ School of Psychology, The University of New South Wales, Sydney, Australia \\ ${ }^{2}$ Department of Clinical Psychology, Radboud University Nijmegen, The Netherlands
}

(Received 23 April 2013; accepted 9 September 2013)

In social anxiety the psychological self is closely related to the feared stimulus. Socially anxious individuals are, by definition, concerned about how the self is perceived and evaluated by others. As autobiographical memory is strongly related to views of the self it follows that biases in autobiographical memory play an important role in social anxiety. In the present study high $(n=19)$ and low $(n=29)$ socially anxious individuals were compared on autobiographical memory bias, current goals, and selfdiscrepancy. Individuals high in social anxiety showed a bias towards recalling more negative and more social anxiety-related autobiographical memories, reported more current goals related to overcoming social anxiety, and showed larger self-discrepancies. The pattern of results is largely in line with earlier research in individuals with PTSD and complicated grief. This suggests that the relation between autobiographical memory bias and the self is a potentially valuable trans-diagnostic factor.

Keywords: Social anxiety; Autobiographical memory; Memory bias; Anxiety disorders; Cognitive bias.

Memory biases are proposed to play an important role in maintaining social anxiety. Clark and Wells (1995) suggest that people with social anxiety are more prone to recall memories of negative social experiences that support their negative self-image. Similarly, Rapee and Heimberg (1997) propose that perceived performance in social situations is at least partially based on the retrieval of autobiographical memories of negative performance in socially anxious individuals. Interestingly, research into explicit and implicit memory biases for socially threatening cues has yielded few robust findings so far (see Morgan, 2010, for a recent review). It has been suggested that biases in autobiographical memory might be more important in social anxiety than biases for social anxiety-related laboratory stimuli (Morgan, 2010). However, empirical studies on autobiographical memory bias in social anxiety are currently lacking (Morgan, 2010). The present study aimed to contribute to this emerging literature by focusing on autobiographical memory bias in relation to the self construct in the context of social anxiety.

The Self-Memory System (SMS) model of autobiographical memory (Conway \& PleydellPearce, 2000; Conway, Singer, \& Tagini, 2004) has been cited repeatedly in relation to biases in autobiographical memory related to psychopathology (e.g. Sutherland \& Bryant, 2005, for PTSD; Morgan, 2010, for social anxiety). This model is not linked to any specific disorder, and so it provides a framework for understanding the relation between the self and memory from a transdiagnostic perspective. According to the SMS model, the encoding and retrieval of autobiographical memories is guided by the "working

Address correspondence to: Dr Julie Krans, The University of New South Wales, School of Psychology, Sydney NSW 2052, Australia. E-mail: j.krans@unsw.edu.au

Julie Krans is supported by a Rubicon Fellowship from the Netherlands Organisation for Scientific Research (NWO). Data collection was conducted by June de Bree at the Behavioural Science Institute of the Radboud University Nijmegen. The authors are grateful to Richard Heijtenis for his help with programming the study in Inquisit. 
self". The working self is a complex hierarchy of goals and self-images that guides the retrieval of autobiographical memories in relation to the "longterm self". The long-term self includes autobiographical knowledge from past experiences which is organised according to themes or time-periods (Conway \& Pleydell-Pearce, 2000; Conway et al., 2004). The SMS model predicts that retrieval of autobiographical memories is dependent on currently active goals and self-images in the working self shaped by the long-term self. This prediction is especially relevant to social anxiety because the main characteristic of the disorder is a fear of negative evaluation of the self by other social agents (American Psychiatric Association, 2000).

This part of the SMS model has not yet been tested in social anxiety but has received initial support from studies focusing on post-traumatic stress disorder (PTSD). Sutherland and Bryant (2005) tested the relationship between self-defining memories and trauma-related goals. Participants were people with PTSD, trauma-exposed nonPTSD, or non-trauma-exposed control participants. Participants retrieved self-defining memories and listed goals that were most important for them at that time. PTSD participants reported more negative self-defining memories than non-PTSD and control participants, and fewer positive memories than non-PTSD participants. Interestingly, they also reported more trauma-related defining memories than participants who had experienced a trauma but did not develop PTSD. In a regression analysis including depression, anxiety, intrusive memories, avoidance, and trauma-related goals, only the latter uniquely predicted the retrieval of trauma-related self-defining memories.

Sutherland and Bryant (2008) subsequently investigated cued recall from autobiographical memory in traumatised participants with and without PTSD. Participants retrieved specific autobiographical memories in response to positive and negative cue words. Participants further completed a measure of self-discrepancy based on three selfimages as defined by Higgins (1987): the Actual self (the current view of the self), the Ideal self (how one would like to be), and the Ought self (what one should be like). Participants with PTSD retrieved more trauma-related memories overall than participants in the non-PTSD group. The PTSD group also showed greater discrepancies between the Actual self and the Ideal and Ought self compared to the non-PTSD group. Discrepancies between the Ideal and Actual self were highly correlated with the number of trauma-related memories that were retrieved in response to positive cue words. Comparable findings have been reported in the context of complicated grief (a proposed psychological disorder in which bereavement takes a chronic form), such that the condition is linked to personal memories dominated by the loss (Maccallum \& Bryant, 2008) and that loss-related goals are linked to memories of the deceased (Maccallum \& Bryant, 2010).

The findings from these studies support a link between autobiographical memory organisation and the self related to aversive events in individuals chronically affected by the experience. Also, the aforementioned studies provide a methodological framework for the study of autobiographical memory bias in other disorders than PTSD. The present study aimed to extend theory of self and memory (e.g., SMS model; Conway \& PleydellPearce, 2000) to the field of social anxiety. Specifically, this study assessed the association between goals, self-defining memories, and other autobiographical memories in relation to high and low levels of social anxiety.

This is important for two reasons. From a clinical perspective it is important to know whether or not autobiographical memory bias could play a role in social anxiety in order to better understand the disorder. From a theoretical perspective it is important to empirically ascertain that, in abnormal cognition, the relation between the self and autobiographical memory as proposed in the SMS model (Conway \& Pleydell-Pearce, 2000) is not restricted to PTSD, which by definition revolves around an autobiographical event.

Based on the SMS model (Conway \& PleydellPearce, 2000) we hypothesised that participants with high levels of social anxiety, compared to low socially anxious participants, would report more self-defining memories, more goals, and more autobiographical memories related to social anxiety. Further, we hypothesised that social anxietyrelated goals and self-discrepancy would predict social anxiety-related autobiographical memory bias above levels of social anxiety.

\section{METHOD}

\section{Participants}

All participants were students at the Radboud University Nijmegen. Only individuals with high and low levels of social anxiety participated in the study. Social anxiety was measured with the 
Liebowitz Social Anxiety Scale (LSAS; Liebowitz, 1987). First, the LSAS was completed as an online survey through the university's online participant system or was e-mailed to students who stated their interest in participating in the study during active on-campus recruitment. Second, participants with high and low social anxiety according to their LSAS scores were invited to participate. Based on earlier research using extreme groups within student samples (e.g., Lange et al., 2011), participants were classified as having high levels of social anxiety (high SA) with an LSAS score of 27 or higher, and low levels of anxiety (low SA) with an LSAS score of 13 or lower on the fear scale. In total 19 high socially anxious (SA) and 29 low SA participants were included in this study. Participants received course credit or a $€ 10$ gift voucher as reimbursement for their time.

\section{Measures}

Psychopathology. Social anxiety levels were assessed with the Liebowitz Social Anxiety Scale (LSAS; Liebowitz, 1987). This self-report questionnaire contains 24 items that describe social behaviours (e.g., "telephoning in public"). Each behaviour is rated on how much anxiety it provokes on a 4 -point scale $(0=$ none to $3=$ severe $)$ and how often the behaviour is avoided on a 4 -point scale $(0=$ never to $3=$ usually $)$. The internal consistency of the LSAS is high $(\alpha=0.96)$ and it shows good convergent validity and reasonable discriminant validity (Heimberg et al., 1999). Depression was measured with the Beck Depression Inventory-II (BDI-II; Beck, Steer, \& Brown, 1996). This is a 21-item self-report questionnaire with high test-retest reliability and internal consistency are high $(r=0.93$; Beck, Steer, \& Brown, 1996; $\alpha=$.91; Beck, Steer, Ball, \& Ranieri, 1996).

Autobiographical memory cueing task. The autobiographical memory cueing task (AMT) is used to investigate memory bias in memory specificity (whether the memory was related to a specific event, an extended event occurring over several days, or a repeated event), or content, or both (Williams \& Broadbent, 1986). As in Sutherland and Bryant (2008), five negative (hurt, tense, angry, fear, and stress) and five positive (happy, brave, safe, love, and special) cue words were used. Before the actual AMT, participants practised recalling specific autobiographical memories in response to two practice words (egg and chocolate). Participants were instructed to recall a specific memory in response to each of the cue words. The cue words were presented on cards by the experimenter in random order with the restriction that negative and positive words alternated.

The AMT is traditionally used to assess memory specificity and therefore participants are prompted to provide a specific memory (i.e., an event that occurred on one particular day) if they fail to do so on their first attempt. In the present study memory specificity was not the target of investigation. However, in order to remain methodologically consistent with previous studies participants were encouraged to provide a specific memory in the present study. The AMT responses were coded for content (social anxiety-related or not) and valence (negative, positive, ambivalent, or neutral) by two independent raters $(\mathrm{JK}$ and $\mathrm{JdB}$ ) who were blind to group.

Self-defining memories. Participants were asked by the experimenter to recall five memories that are emotional, important, and have a strong relation to who they are as a person today (for literal instructions see Sutherland \& Bryant, 2005). The responses were audio-recorded and transcribed. Similar to the AMT, the memories were coded for content (social anxiety-related or not) and valence (negative, positive, or ambivalent).

Goals. Participants were asked to list 15 goals that represent "the things that are most important for you to achieve at this time" (Emmons, 1986; Sutherland \& Bryant, 2005). In Table 1 examples are presented for social anxiety-related cued autobiographical memories, self-defining memories and goals.

Self-discrepancy. To measure self-discrepancy, a computerised version of the Self-Strength Guide was used (Higgins, Shah, \& Friedman, 1997; Holmes, Lang, \& Shah, 2009). Participants generated six characteristics that they would ideally like to possess (Ideal self) and six characteristics that they believed they should possess (Ought self). Participants rated the importance of each characteristic as well as the extent to which they felt they already possessed this characteristic. Ideal-Actual self-discrepancy was defined as the summed difference between the Actual self scores and the Ideal self scores. Ought-Actual selfdiscrepancy was defined as the summed difference 
TABLE 1

Examples of autobiographical memories on the AMT, self-defining memories, and goals that were coded as related to social anxiety

\begin{tabular}{|c|c|c|}
\hline Autobiographical memories on the AMT & Self-defining memories & Goals \\
\hline \multicolumn{3}{|l|}{ (cue word: stress) } \\
\hline $\begin{array}{l}\text { The first time I met my supervisor I went there and } \\
\text { I thought "what is she expecting that I already } \\
\text { know?" and I was super stressed about that, that } \\
\text { maybe she would think I was stupid. }\end{array}$ & $\begin{array}{l}\text { We had a sleep-over. It was kind of fun, but at some } \\
\text { point I shut down or something. That I suddenly } \\
\text { thought "I'm not fun". That I just saw everyone } \\
\text { talking to each other and all I thought was "I can't } \\
\text { do that". }\end{array}$ & Be more confident \\
\hline \multicolumn{3}{|l|}{ (cue word: brave) } \\
\hline $\begin{array}{l}\text { Yesterday I went to the supermarket to buy } \\
\text { cigarettes; that was really hard. }\end{array}$ & $\begin{array}{l}\text { I told on my brother and he and his friends sprayed } \\
\text { me with bug spray. Because they thought I am like a } \\
\text { mosquito: very skinny and very annoying. }\end{array}$ & Reduce the fear to fail \\
\hline \multicolumn{3}{|l|}{ (cue word: hurt) } \\
\hline $\begin{array}{l}\text { My friends were going on a holiday, but they did } \\
\text { not ask if I would come. That hurt me. }\end{array}$ & $\begin{array}{l}\text { In high school, in second year, a teacher told me } \\
\text { "you can't do this. You cannot do the A levels." }\end{array}$ & $\begin{array}{l}\text { Become more } \\
\text { assertive }\end{array}$ \\
\hline
\end{tabular}

between the Actual self scores and the Ought self scores (Holmes et al., 2009).

\section{Procedure}

All measures were presented on a PC using Inquisit 3 (Millisecond software), except the AMT and self-defining memories, which were administered face-to-face by the experimenter. Participants first completed symptom severity measures (BDI-II and LSAS) and then continued with the AMT, self-defining memories, goal listing, and selfdiscrepancy measure. The latter four tasks were administered in random order for each participant. Afterwards, participants were debriefed and thanked for their participation.

\section{RESULTS}

\section{Statistical approach}

Group differences were tested using independent samples $t$-tests. In cases of unequal variance the corrected $t$-value is reported. Analyses were regarded as significant where $p<.05$. Effect size Cohen's $d$ is reported for all significant $t$-tests. Means and standard deviations across and within groups are reported in Table 2.

\section{Inter-rater reliability}

For the responses on the Autobiographical Memory Task (AMT) the inter-rater reliability (Spearman correlation) was $r_{s}=.806(p<.001)$ for valence

TABLE 2

Descriptive statistics for the high and low socially anxious groups

\begin{tabular}{|c|c|c|c|c|c|c|}
\hline & \multicolumn{2}{|c|}{ High social anxiety } & \multicolumn{2}{|c|}{ Low social anxiety } & \multicolumn{2}{|c|}{ Total } \\
\hline & $M$ & $S D$ & $M$ & $S D$ & $M$ & $S D$ \\
\hline Age & 20.89 & 2.26 & 22.41 & 3.43 & 21.81 & 3.09 \\
\hline LSAS fear & 35.16 & 7.10 & 7.00 & 3.64 & 18.15 & 14.86 \\
\hline LSAS avoidance & 26.47 & 8.95 & 7.69 & 5.27 & 15.13 & 11.55 \\
\hline BDI-II & 11.16 & 4.92 & 3.03 & 3.29 & 6.26 & 5.64 \\
\hline Number of negative memories on the AMT & 5.26 & 0.81 & 4.31 & 1.00 & 4.69 & 1.03 \\
\hline Number of negative memories in response to positive cues on the AMT & 1.68 & 1.06 & 1.45 & 0.87 & 1.54 & 0.94 \\
\hline Number of positive memories in response to negative cues on the AMT & 0.00 & 0.00 & 0.41 & 0.63 & 0.25 & 0.53 \\
\hline Number of social anxiety-related memories on the AMT & 2.47 & 1.65 & 0.41 & 0.68 & 1.23 & 1.53 \\
\hline Number of negative self-defining memories & 2.89 & 1.14 & 1.76 & 0.95 & 2.21 & 1.67 \\
\hline Number of social anxiety-related self-defining memories & 2.32 & 1.16 & 0.69 & 1.00 & 1.33 & 1.33 \\
\hline Number of social anxiety-related goals & 3.37 & 1.89 & 1.28 & 1.13 & 2.10 & 1.79 \\
\hline Ideal-Actual self-discrepancy & 8.58 & 3.04 & 4.86 & 2.23 & 6.33 & 3.14 \\
\hline Ought-Actual self-discrepancy & 8.42 & 3.13 & 4.52 & 2.28 & 6.06 & 3.25 \\
\hline
\end{tabular}


and $r_{s}=.758(p<.001)$ for content. For the selfdefining memories the inter-rater reliabilities were $r_{s}=.907(p<.001)$ and $r_{s}=.849(p<.001)$, for valence and content, respectively. Content interrater reliability for current goals was $r_{s}=.815$ $(p<.001)$. Disagreements were resolved through discussion and the agreed-upon scores were used in the statistical analyses.

\section{Demographic characteristics}

There was no statistical difference in age between the low SA and high SA groups, $t(46)=1.70, p=$ .10 , although there was a trend towards low SAs being slightly older. The low SA group contained five men and 24 women and the high SA group contained two men and 17 women; $\chi^{2}(1)=0.42$, $p=.52$.

\section{Group check}

As expected, participants in the high SA group had significantly higher scores on the fear subscale of the LSAS than participants in the low SA group, $t(24.28)=15.96, p<.001$. Similarly, high SA participants had significantly higher LSAS avoidance scores than low SA participants, $t(26.24)=8.26, p<.001$. The high SA group also showed higher levels of depression on the BDI-II compared to the low SA group, $t(46)=6.86$, $p<.001$.

\section{Memory recall bias}

Autobiographical Memory Task. An independent samples $t$-test indicated that the high SA group recalled more negative memories on the AMT than the low SA group, $t(46)=3.47, p=.001$, $d=1.05$.

We tested whether high SA participants also recalled more negative memories in response to positive cue words compared to low SAs. This was not the case, $t(46)=0.84, p=.40$. In contrast, low SAs recalled more positive memories in response to negative cue words than the high SA group, $t(28)=3.55, p=.001, d=1.30$.

As predicted, high SAs recalled more memories on the AMT that were related to social anxiety compared to low SAs, $t(22.10)=5.17, p<.001$, $d=1.77$.
Self-defining memories. An independent samples $t$-test indicated that high SAs recalled more negative self-defining memories than the low SAs, $t(46)=3.73, p=.001, d=1.08$. Also as predicted, the high SA group on average reported more selfdefining memories related to social anxiety than the low SA group, $t(46)=5.17, p<.001, d=1.50$.

Goals. An independent samples $t$-test indicated that the high SA group reported more social anxiety-related goals than low SA participants, $t(46)=4.80, p<.001, d=1.38$. The number of social anxiety-related goals was significantly correlated with the LSAS fear subscale: $r=.59, p<$ .001 ; LSAS avoidance subscale: $r=.51, p<.001$, BDI-II: $r=.57, p<.001$; number of social anxiety memories on the AMT: $r=.32, p=.03$; number of negative self-defining memories: $r=.51, p<.001$; and number of social anxiety self-defining memories: $r=.41, p=.004$. Social anxiety-related goals were only correlated at trend level with the number of negative memories recalled on the AMT: $r=.26, p=.08$.

Self-discrepancy. High SAs showed greater Ideal-Actual self-discrepancy and Ought-Actual self-discrepancy compared to low SAs; $t(46)=$ $4.88, p<.001, d=1.41$, and $t(46)=5.00, p<.001$, $d=1.44$, respectively.

Ideal-Actual self-discrepancy was significantly and positively correlated with LSAS fear subscale: $r=.67, p<.001$; LSAS avoidance subscale: $r=.66, p<.001$, BDI-II: $r=.67, p<.001$; number of negative memories on the AMT: $r=.36, p=.01$; number of social anxiety-related memories on the AMT: $r=.52, p<.001$; and number of social anxiety-related self-defining memories: $r=.46, p=$ .001 . Ideal-Actual self-discrepancy was only marginally significantly correlated with the number of negative self-defining memories: $r=.28, p=.06$.

Ought-Actual self-discrepancy was significantly and positively correlated with LSAS fear subscale: $r=.68, p<.001$; LSAS avoidance subscale: $r=.61$, $p<.001$; depression on the BDI-II: $r=.76$, $p<.001$; number of negative memories on the AMT: $r=.49, p<.001$; number of social anxietyrelated memories on the AMT: $r=.55, p<.001$; and number of social anxiety-related self-defining memories: $r=.44, p<.001$. Ought-Actual selfdiscrepancy was only marginally correlated with the number of negative self-defining memories: $r=.28, p=.06$.

Predictors of social anxiety-related memory recall. To test which variables were predictive of 
the number of social anxiety-related memories recalled on the AMT, a hierarchical linear regression analysis was conducted with Step 1 including LSAS fear, LSAS avoidance, and BDI-II scores; Step 2 including the self-discrepancy scores; and Step 3 including social anxiety-related goals. Only the first model (including LSAS fear, LSAS avoidance, and BDI-II scores) showed significant predictive value, $R_{\text {change }}^{2}=0.53, F_{\text {change }}(3,44)=$ $16.84, p<.001$. Within this block, only LSAS fear reached significance as an independent predictor, $\beta=.51, t=2.10, p=.04$.

To test which variables were predictive of the number of social anxiety-related self-defining memories, a similar regression analysis was done with the number of social anxiety self-defining memories as the dependent variable. Again, only the first model (LSAS fear, LSAS avoidance, BDI-II) showed significant predictive value, $R_{\text {change }}^{2}=0.38, F_{\text {change }}(3,44)=9.02, p<.001$. Within this block, only LSAS fear was a significant predictor, $\beta=.62, t=2.14, p=.04$.

\section{DISCUSSION}

In line with predictions, participants high in social anxiety recalled more negative memories and more memories related to social anxiety than the low socially anxious group on the AMT. Unlike the findings in PTSD patients by Sutherland and Bryant (2008), high socially anxious participants did not recall more negative memories in response to positive cue words than low socially anxious participants. Rather, low socially anxious participants recalled more positive memories in response to negative cue words. It is possible that students who enjoy minimal social anxiety have fewer negative experiences to draw on, and consequently tend to retrieve positive memories in response to cues that one might normally expect to elicit a negative recollection.

As predicted, the high socially anxious participants reported more negative self-defining memories, and more self-defining memories related to social anxiety compared to the low socially anxious participants. That is, the socially anxious participants incorporated negative social experiences into their identity to a higher degree than the low socially anxious participants. This mirrors the findings in PTSD (Sutherland \& Bryant, 2008) and complicated grief (Maccallum \& Bryant, 2010). The findings support the Self-Memory
System model of autobiographical memory (SMS model; Conway \& Pleydell-Pearce, 2000) in which a dynamic and bidirectional relation between the self and memory retrieval is described. That is, an individual with PTSD is more likely to report trauma-related experiences when asked to recall memories that are relevant to their identity. Similarly, the findings of the present study show that socially anxious individuals recall more memories related to socially anxious experiences when asked to define themselves than do individuals with lower levels of social anxiety.

Our prediction that participants high in social anxiety would report more current goals related to their social anxiety than the low socially anxious participants was also supported. According to the SMS model (Conway \& Pleydell-Pearce, 2000), the working self interacts between the long-term self and autobiographical memory through currently held goals. That is, memories related to current pursuits are thought to be highly accessible, which was underscored by our findings. As would be expected from an interactive relationship between the self, memory and current goals, all measures were significantly and positively related to the level of social anxiety symptoms. However, in contrast to the Sutherland and Bryant (2005) study, social anxiety-related goals did not predict the retrieval of social anxiety-related autobiographical memories (on the AMT or the selfdefining memories task) over current levels of social anxiety, which was the only significant predictor in a regression analysis.

As predicted, self-discrepancy (Actual and Ought) was significantly greater in the high socially anxious group and was positively and significantly correlated with the recall of social anxiety-related autobiographical memories on the AMT as well as for social anxiety-related selfdefining memories. Similar to the goals, however, self-discrepancy did not predict social anxietyrelated recall over current levels of social anxiety. These findings are different from the pattern found in the sample of PTSD patients (Sutherland \& Bryant, 2005, 2008), in which goals and selfdiscrepancy were significant predictors of traumarelated recall over symptoms levels of PTSD. Several explanations may exist for this difference. Whereas we studied students with varying levels of social anxiety, Sutherland and Bryant (2005) studied treatment-seeking patients diagnosed with PTSD. It is also possible that the dominant effect of trauma on people who develop PTSD may be stronger than the influence of social concerns on 
people who experience social anxiety. Further, traumatised individuals may have a more concrete striving in relation to self-discrepancy as they can compare their "pre-trauma" self to a "posttrauma" self. In social anxiety, personal strivings may be of a more global nature (e.g., "more confident") and may not have a concrete example of a better self. The idea that goals exist in the working self at different levels of abstractness/ concreteness has been previously put forward within the SMS model (Conway, Meares, \& Standart, 2010). Further, goal specificity is related to goal commitment (e.g., Wright \& Kacmar, 1994) which could indicate that the working self would have a more important role in PTSD than in social anxiety.

Research has now shown that autobiographical memory bias is present in PTSD (Sutherland \& Bryant, 2005, 2008), complicated grief (Maccallum \& Bryant, 2008, 2010), and social anxiety (this paper). These participants also tended to view their "self" in light of their disorder. This suggests that the relation between the self and autobiographical memory should be taken into account as a trans-diagnostic factor, i.e., a factor that has clinical significance across multiple disorders. For clinical purposes, it seems warranted to assess autobiographical memory bias and self-image as meaningful variables in PTSD, complicated grief, and social anxiety that should change over the course of successful treatment. The research findings further suggest that memory bias and negative self-image could be important targets in psychological treatment regardless of, but with consideration for, the specific disorder.

This study has several limitations. For one, the different tasks might have had a carry-over effect that was not accounted for by counterbalancing the measures. We decided to administer the tasks in one session in order to be better able to relate our results to the Sutherland and Bryant studies (2005, 2008). Nevertheless, future studies should consider administering the measures in different sessions if possible. Second, the sample size was rather small, but we also note here that effect sizes for group differences were large. Third, the low socially anxious group may have characteristics that differ from the average because they represent an extreme group. Similarly, the high social anxiety group were not administered a structured clinical interview to determine Social Anxiety Disorder. We chose to compare a high and low socially anxious group based on the typical procedure of earlier studies that included non-clinical samples (e.g., Lange et al., 2011). It is therefore important to view the group differences in this study as relative differences. Finally, the design of the study is correlational in nature and therefore provides no information about potential causal relationships. The question remains whether memory influences the self in the same way that the self is related to memory in social anxiety. Future studies using experimental design can shed more light on this question of causality.

To summarise, we tested whether the relation between the self and autobiographical memory bias in PTSD and complicated grief could also be found in social anxiety. We found evidence for a similar relation where high socially anxious participants incorporated memories of socially anxious events into their identity. The findings supported an autobiographical memory bias towards socially anxious memories in the high anxious group. The findings of this study extend the Self-Memory System model of autobiographical memory (Conway \& Pleydell-Pearce, 2000) into the field of social anxiety. The findings also contribute to emerging literature supporting the notion that memory bias in social anxiety may be particularly relevant in the domain of autobiographical memory (Clark \& Wells, 1995; Morgan, 2010; Rapee \& Heimberg, 1997). Finally, future studies that administer the tasks at different sessions and studies using experimental designs to uncover the causal mechanisms behind the relationship between memory and the self in social anxiety are necessary.

\section{REFERENCES}

American Psychiatric Association. (2000). Diagnostic and Statistical Manual of mental disorders (IV-TR). Washington, D.C.: APA.

Beck, A. T., Steer, R. A., Ball, R., \& Ranieri, W. F. (1996). Comparison of Beck Depression Inventories -IA and -II in psychiatric outpatients. Journal of Personality Assessment, 67, 588-597.

Beck, A. T., Steer, R. A., \& Brown, G. K. (1996). Manual for the Beck Depression Inventory-II. San Antonio, TX: Psychological Corporation.

Clark, D. M., \& Wells, A. (1995). A cognitive model of social phobia. In R. G. Heimberg, M. Liebowitz, D. A. Hope, \& F. R. Schneider (Eds.), Social phobia: Diagnosis, assessment, and treatment. (pp. 69-92). New York, NY: Guilford Press.

Conway, M. A., Meares, K., \& Standart, S. (2010). Images and goals. Memory, 12, 525-531.

Conway, M. A., \& Pleydell-Pearce, C. W. (2000). The construction of autobiographical memories in the Self-Memory System. Psychological Review, 107, 261-288. 
Conway, M. A., Singer, J. A., \& Tagini, A. (2004). The self and autobiographical memory: Correspondence and coherence. Social Cognition, 22, 491-529.

Emmons, R. A. (1986). Personal strivings: An approach to personality and subjective well-being. Journal of Personality and Social Psychology, 51, 1058-1068.

Heimberg, R. G., Horner, K. J., Juster, H. R., Safren, S. A., Brown, E. J., Schneier, F. R., \& Liebowitz, M. R. (1999). Psychometric properties of the Liebowitz Social Anxiety Scale. Psychological Medicine, 29, 199-212.

Higgins, E. T. (1987). Self-discrepancy: A theory relating self and affect. Psychological Review, 94, 319-340.

Higgins, E. T., Shah, J., \& Friedman, R. (1997). Emotional responses to goal attainment: Strength of regulatory focus as a moderator. Journal of Personality and Social Psychology, 72, 515-525.

Holmes, E. A., Lang, T. J., \& Shah, D. M. (2009). Developing interpretation bias modification as a "cognitive vaccine" for depressed mood: Imagining positive events make you feel better than thinking about them verbally. Journal of Abnormal Psychology, 118, 76-88.

Lange, W.-G., Heuer, K., Langner, O., Keijsers, G. P. J., Becker, E. S., \& Rinck, M. (2011). Face value: Eye movements and the evaluation of facial crowds in social anxiety. Journal of Behavior Therapy and Experimental Psychiatry, 42, 355-363.
Liebowitz, M. R. (1987). Social phobia. Modern Problems in Pharmacopsychiatry, 22, 141-173.

Maccallum, F., \& Bryant, R. A. (2008). Self-defining memories in complicated grief. Behaviour Research and Therapy, 46, 1311-1315.

Maccallum, F., \& Bryant, R. A. (2010). Impaired autobiographical memory in complicated grief. Behaviour Research and Therapy, 48, 328-334.

Morgan, J. (2010). Autobiographical memory biases in social anxiety. Clinical Psychology Review, 30, 288-297.

Rapee, R. M., \& Heimberg, R. G. (1997). A cognitivebehavioural model of anxiety in social phobia. Behaviour Research and Therapy, 35, 741-756.

Sutherland, K., \& Bryant, R. A. (2005). Self-defining memories in post-traumatic stress disorder. British Journal of Clinical Psychology, 44, 591-598.

Sutherland, K., \& Bryant, R. A. (2008). Autobiographical memory and the self-memory system in posttraumatic stress disorder. Journal of Anxiety Disorders, $22,555-560$.

Williams, J. M. G., \& Broadbent, K. (1986). Autobiographical memory in suicide attempters. Journal of Abnormal Psychology, 95, 144-149.

Wright, P. M., \& Kacmar, K. M. (1994). Goal specificity as a determinant of goal commitment and goal change. Organisational Behaviour and Human Decision Processes, 59, 242-260. 